\title{
Perceived Stress Level and Coping Mechanisms Among Health Allied Students
}

\author{
Abd Alhadi Hasan ${ }^{1}$, Hussein Alqarni ${ }^{2} \&$ Nofaa Ali Alasmee ${ }^{3}$ \\ ${ }^{1}$ Assistant professor in psychiatric and Mental Health Nursing, Nursing Department, Fakeeh College for Medical \\ Sciences, Jeddah, Saudi Arabia \\ ${ }^{2}$ MSc of Advanced Nursing, teaching assistant in Adult Health Nursing Department, King Khalid University, \\ Abha, Saudi Arabia \\ ${ }^{3}$ Assistant professor in Mental Health Nursing, Nursing College, King Abdulaziz University, Jeddah, Saudi \\ Arabia \\ Correspondence: Abd Alhadi Hasan, Assistant professor in psychiatric and Mental Health Nursing, Nursing \\ Department, Fakeeh College for Medical Sciences, Jeddah, Saudi Arabia.
}

Received: November 3, 2019 Accepted: January 11, 2020 Online Published: July 6, 2020

doi:10.5539/gjhs.v12n9p50 URL: https://doi.org/10.5539/gjhs.v12n9p50

\begin{abstract}
Purposes: This study identified and compared between the levels and types of stressors as well as coping behaviors.

Design: Cross-Sectional Survey

Methods: Data were collected using a convenience sample of 286 students

Findings: The results showed that "teachers and nursing staff" 'and "assignments and workload" were the highest sources of stress among nursing and MLS students. But this was much higher among nursing students. In addition, lack of professional knowledge and skills were cited the least stressors among both students' groups.

Practice Implications: The result can be used to support Nursing student to utilize positive coping mechanism to deal with stress successfully. Enhance academic staff awareness about re-allocation of the academic demands and the emphasis on the benefit of orientation week for the students.
\end{abstract}

Keywords: perceived stress, coping mechanism, students, education, University, Cross-sectional

\section{Introduction}

Empirical research supports the view that the learning environment is stressful (McCarthy et al., 2018; Singh et al., 2013; Zhao et al., 2015). Lazarus and Folkman (1984) defined stress as reaction of the person to the environment in terms of threat, danger and wellbeing. Stress appears as the output of an individual interpretation of events and the availability of coping mechanisms to deal with it (Deasy et al., 2014). The primary appraisal of the Lazarus model refers to the initial perception of the stressor and it is evaluated as inhibitive, supportive or benign. The secondary appraisal involves the coping mechanism (Lazarus \& Folkman 1984; Lazarus \& Folkman, 1987).

\subsection{Review of Literature (Nursing Students)}

The interaction between the primary and secondary appraisal systems determines the final impact of the stressor on the individual. However, it influenced by interplay factors such as perceived support, the coping mechanism and self-efficacy (Bradshaw et al., 2018). A coping mechanism is defined as a cognitive, emotional and behavioural appraisal of the stressor in an encounter with internal or external demands in a specific situation. Student nurses cannot avoid stressors entirely (Folkman \& Lazarus, 1980). However, their coping styles determine their reaction to the stressors (Galvin \& Smith, 2015). This model proposed two strategies of coping mechanism: problem based or emotional based. Chan et al. (2014) reported that nursing students who used emotional coping mechanisms to cope with stress experienced more negative consequences of stress on their health, compared with the problem-solving technique. Likewise, Ab Latif and Nor (2016) indicated that an escape-avoidance coping mechanism is associated a detrimental impact on mental health among Japanese student nurses.

The coping mechanism plays a key role in determining the outcome of the stressor by reducing, minimizing or 
tolerating stress which may prevent psychological distress (Mivšek et al., 2018; Seyedfatemi et al., 2007). It has been demonstrated that university students adopt different ways of handling stressors, which can be considered as effective (positive) or ineffective (negative) (McCarthy et al., 2018; Subhi Al-Zayyat \& Al-Gamal, 2014; Tully, 2004). Some effective coping mechanisms include seeking social support and using leisure activities; maladaptive coping strategies include avoidance and escape (McCarthy et al., 2018; Subhi Al-Zayyat \& Al-Gamal, 2014; Tully, 2004). The perceived level of social support has been explored and found to predict wellbeing. Interestingly, Galvin and Smith (2015) investigated the impact of stress on 100 Australian and New Zealand student nurses over three years, concluding that their wellbeing was determined by the type of coping mechanism and available emotional support. A study conducted by Shaban et al. (2012) reported that student nurses who employed adaptive coping strategies (i.e. problem solving) to manage stressors encountered in the clinical course of their nursing programme experienced a low level of psychological distress. Conversely, those who utilized a maladaptive strategy showed a higher level of psychological distress (Tully, 2004).

There is a dearth of research into stress and coping mechanisms among student nurses at different levels, or among other allied health professionals such as Medical Laboratory Science (MLS) students. Therefore, this study is considered imperative to reflect Saudi nursing and MLS students' stress level and use of coping mechanisms to handle stressors. There is increasing concern to determine perceived stress levels in educational environments, and the consequences for students' health and wellbeing, particularly in Western countries. Stress can compromise the learning process, memory, concentration and performance level (Kuoppala et al., 2008; Zhao et al., 2015). Previous studies indicated that student nurses experience stress during their education and attribute it to a wide range of factors, including clinical training (Pryjmachuk \& Richards, 2007). Evidence suggests that the stress sources identified are similar to those experienced by general students (Pulido-Martos et al., 2012). Stressors can be categorized as academic or workload; the former include examinations, assessment and the timing of exams, although the latter source of stress is more prevalent among student nurses (McCarthy et al., 2018).

Undoubtedly, clinical training is the cornerstone of undergraduate nursing education. However, students may also meet challenges or threats in the practice environment, namely using technological equipment, establishing and maintaining good relationships with clinical instructors and healthcare providers in hospitals, rapid deterioration of patients' medical condition, academic workload and fear of examinations (McKenna \& Plummer, 2013). Research indicate that nurses suffer from a higher level of stress and associated physical and psychological symptoms than students in other disciplines, such as engineering (Behere et al., 2011; Elias et al., 2011). The study by Zhao et al. (2015) highlighted that the majority of the student nurses' time in their final year is devoted to the practice of nursing skills in the hospital.

International literature suggests that the level of psychological distress is reported more frequently among higher education students than the general population. In addition, female students experience more psychological distress than male students (Nechita et al., 2014). However, these findings need to be interpreted with caution as the researchers have utilized a wide range of instruments to measure psychological distress, and different cut-off points to determine it. From the health promotion and prevention perspective, psychological distress may be linked with risk behaviours and physical illness among students, or it may progress to become an enduring mental illness. As a result, stress is an important area of research in educational settings, where the students' learning and functioning are interrupted. More importantly, stress is frequently prescribed as a major reason of attrition among student nurses (Brown and Marshall, 2008; Cameron et al., 2011).

Burnard et al. (2008) compared the stress level and its sources among student nurses in five countries. Although participants had different cultural backgrounds, the results showed that they all reported a similar experience of stress (Tully, 2004). Data from several studies suggest that the clinical part of core nursing courses is associated with a high level of stress, particularly during the first clinical placement (Chernomas \& Shapiro, 2013). The outcomes of stressors depend on the extent of the ability to cope with the stimulus. When students fail to cope effectively with stressors, not only their work and health but also their attitude and satisfaction in being a nurse are affected (Tully, 2004). Cognitive behavioural coping strategies are the most cited to reduce stress (Galvin \& Smith, 2015; Kaviani et al., 2007). Inevitably, students cannot escape from these stressors. However, in stress-coping models, the extent and method of coping with demands is more important than the origin of the stress itself (Lazarus and Folkman 1984). Studying stress and coping mechanisms among student nurses would therefore be especially interesting for higher education administrators. In this sense, coping is the cognitive and behavioural effort aimed to master, improve, tolerate, resist or reduce either internal or external demands or conflict. It has been demonstrated that the level of appraisal of demands by someone determines stress levels and the coping strategies employed (Lazarus \& Folkman 1984). 


\subsection{Review of Literature (Medical Laboratory Science Students)}

Considering the impact of stress on them, it is therefore imperative to understand student nurses' experience of stress and determine the stressors and their coping mechanisms. The extensive literature focuses largely on students from Western countries. For example, one study revealed that the majority of American MLS student experience mild to moderate levels of depression, while a recent Japanese study by Yamashita et al. (2012) indicated that level of depression was higher in Japan than America, using the Beck Depression Inventory. This may be explained by the variation in teaching strategies between the US and Japan as well as the availability of academic and financial support. This stressor posits the high level of stress on the students as they are required to adapt to the new learning environment, and they may lack adequate clinical skills to perform nursing procedures. Perceived stress is a common problem with negative consequences on individual life, including mental and physical illnesses, sleep disorders, irritability, headaches and recurrent infection (Braga et al., 2012). Consistently, students who experience psychological symptoms are more likely to report symptoms of depression when they have ineffective coping strategies (Pryjmachuk \& Richards, 2007; Yusoff et al., 2010). However, there is a limited number of studies investigated the perceived stress and coping mechanisms among MLS students.

The World Health Organization (WHO) estimated that stress-related disorders will be one of the leading causes of disability by 2020 (Al-Lamki, 2010). There is a consensus among social scientists that nursing schools are now considered as a stressful environment with a detrimental impact on the students' psychological wellbeing and their academic achievement (Galvin \& Smith, 2015; Gibbons et al., 2011). Studies from different parts of the world recognize that student nurses suffer from severe levels of anxiety and stress.

Although studies indicate similar sources of stress for students and qualified staff nurses, stress recognised as a determinant of psychological distress among university students with stressors including poor employment prospects, technology overload and job pressure (Nayomi, 2016). More specifically, studying a programme with clinical components described as a significant determinants of stress among undergraduate students (Zhao et al., 2015), especially nurses Similarly, Subhi Al-Zayyat and Al-Gamal (2014) concluded that lack of experience, the intrinsic demands of psychiatric nursing education and the challenge of daily living were sources of stress among undergraduate student nurses. From my point of view, this may be attributed to the social stigma and stereotyping attached to mental illness. The negative attitudes towards mental illness have a strong influence on student learning outcomes or establishing a therapeutic relationship with patients (McCarthy et al., 2018; Nolan \& Ryan, 2008; Subhi Al-Zayyat \& Al-Gamal, 2014).

At the Fakeeh College for Medical Sciences, the nursing programme has 134 credit hours divided over four years, and students commence their hospital training in the first year. In MLS 126 credit hours are divided over four years, with clinical courses starting in the third and fourth years.

\subsection{Study Aims and Research Questions}

The purpose of this study was to determine the stress level, type of stressors and coping mechanisms adopted by nursing and MLS students registered in the X?? at the beginning and end of their course.

1) What are the stress levels, nature of stressor, and the coping mechanisms used by the study participants?

2) Do the stress level, types of stressor and coping mechanisms vary between the study participants?

\section{Methodology}

\subsection{Study Design}

This study was employed a descriptive explanatory design.

\subsection{Setting}

The study was conducted at $\mathrm{X}$, where students in both programmes represent a wide range of socio-economic status.

\subsection{Participants}

Undergraduate Nursing and MLS students were the target population of the study who were enrolled at X in the first semester of the academic year 2017-2018. The inclusion criteria are current students at X, registered on appropriate courses, and able to speak Arabic or English.

\subsection{Outcome Measure}

\subsubsection{Socio-Demographic Data}

All students were asked to complete a demographic information sheet, including data on gender, age, education 
level, and living status.

\subsubsection{Perceived Stress Scale (PSS)}

The PSS has 29 items focusing on six domains: stressors encompassing patient care, teacher and staff, assignments and workload, peers and daily life, lack of professional skills and knowledge, and clinical environment (Sheu, 1997). Each item is rated on a five-point Likert scale, with possible scores ranging from 0 to 116; a higher score indicates a perceived higher level of stress. This scale has a Cronbach's alpha of 0.89 and test-retest reliability of 0.83 (Sheu et al., 2002). The Cronbach's alpha of the Arabic version is 0.89 and CVI is $100 \%$ (Subhi Al-Zayyat \& Al-Gamal, 2014).

\subsubsection{Coping Behaviour Inventory (CBI)}

CBI determines the strategies coping adopted by student nurses. It has 19 items measuring four dimensions: problem-solving behaviours, avoidance behaviour, optimistic coping behaviour and transference behaviour (Sheu et al., 2002). Each item rated on a five-point Likert scale from 0 to 4. Students who achieved a higher score indicates recurrent use of a certain type of coping mechanism. Cronbach's alpha is 0.76 , and for the Arabic version is 0.74 (Subhi Al-Zayyat \& Al-Gamal, 2014).

\subsection{Ethical Considerations}

Ethical approval was sought from the Research and Ethics Committee of Fakeeh College for Medical Sciences. The participants were informed about the voluntary nature and their right to withdraw at any point. Participants' privacy and confidentially were assured and their names would not appear on any documents in the study.

\subsection{Data Analysis}

Data were analyzed using the Statistical Package for the Social Sciences (SPSS) version 23 for Windows. The level of significance for all analysis was set at $\mathrm{p}<0.05$. The first stage of the quantitative data analysis was on the participants' responses to the variables. The next stage employed descriptive statistics (mean, standard deviation) to analyze social demographic characteristics as well as the stress level and ways of coping with stress. The magnitude.

\section{Results}

The total numbers of nursing and MLS students was 268, with a response rate of $87 \% .126$ of the participants were enrolled in the nursing programme and 160 in the MLS programme. All the study participants from both programmes were female and aged less than 20 years. Approximately two-thirds of the nursing students were in the initial phases of their study compared with $43 \%$ of MLS students. The study participants data presented in Table 1.

Table 1. Socio-demographic characteristics of the study participants

\begin{tabular}{|c|c|c|c|c|}
\hline \multirow{2}{*}{ Characteristics } & \multicolumn{2}{|c|}{ Initial Nursing $(\mathrm{n}=126)$} & \multicolumn{2}{|c|}{ Advance $(\mathrm{n}=160)$} \\
\hline & Frequency & $\%$ & Fequency & $\%$ \\
\hline \multicolumn{5}{|l|}{$\leq 20$} \\
\hline $21-30$ & 64 & $75.3 \%$ & 86 & $53.8 \%$ \\
\hline $31-40$ & 43 & $24.7 \%$ & 74 & $46.3 \%$ \\
\hline \multicolumn{5}{|l|}{$41-50$} \\
\hline \multicolumn{5}{|l|}{$\geq 50$} \\
\hline \multicolumn{5}{|l|}{ Gender } \\
\hline \multicolumn{5}{|l|}{ Male } \\
\hline Female & 107 & $100 \%$ & 160 & $100 \%$ \\
\hline \multicolumn{5}{|l|}{ Ways of choosing program } \\
\hline Self-selection & 87 & $69.0 \%$ & 105 & $65.6 \%$ \\
\hline Job security & 18 & $14.8 \%$ & 37 & $23.1 \%$ \\
\hline Others & 21 & $16.6 \%$ & 18 & $11.3 \%$ \\
\hline \multicolumn{5}{|l|}{ Living status } \\
\hline With family & 118 & $93.6 \%$ & 148 & $92.5 \%$ \\
\hline With Roommate or alone & 8 & $6.4 \%$ & 12 & $7.5 \%$ \\
\hline
\end{tabular}


Table 2. Perceived stress among initial and advance nursing students at baseline and at the end of the semester.

\begin{tabular}{llllll}
\hline & \multicolumn{2}{c}{ Initial students } & \multicolumn{2}{c}{ Advance students } & p \\
\cline { 2 - 5 } & Baseline & End of the semester & Baseline & End of the semester \\
\hline Stress from teachers and nursing staff & 3.75 & 3.62 & 2.76 & 2.53 & $0.03 *$ \\
Stress from the assignment and workload & 3.24 & 3.12 & 2.27 & 2.01 & $0.03 *$ \\
Clinical environment & 3.08 & 2.97 & 2.07 & 1.69 & $0.02^{*}$ \\
Taking care of patients & 3.12 & 3.04 & 1.88 & 1.76 & $0.01^{*}$ \\
Peers and daily life & 2.37 & 2.33 & 1.78 & 1.69 & $0.04 *$ \\
lack of professional knowledge and skills & 2.02 & 2.12 & 1.47 & 1.24 & $0.03 *$ \\
\hline$* p<0.05$ & & & & &
\end{tabular}

Table 3. Adopted coping mechanism among nursing and MLS students at baseline and at the end of the semester

\begin{tabular}{llllll}
\hline & \multicolumn{2}{l}{ Initial students } & \multicolumn{2}{l}{ Advance students } \\
\cline { 2 - 5 } & Baseline & End of the semester & Baseline & End of the semester & $0.02^{*}$ \\
\hline Avoidance & 3.54 & 2.54 & 1.47 & 1.12 & 0.12 \\
Stay optimistic & 3.14 & 3.07 & 3.22 & 3.17 & $0.03^{*}$ \\
Problem solving & 2.15 & 3.24 & 3.62 & 3.70 & 0.14 \\
Transference & 1.77 & 1.12 & 1.24 & 1.02 & 0 \\
\hline
\end{tabular}

$* p<0.05$.

\subsection{Difference in the Perceived Stress Level and Type of Stressors Between Nursing and MLS Students at Baseline and End of the Semester}

The result of the data analysis revealed that the average stress level experienced by student nurses was statistically significantly higher than that for MLS students, both at the baseline and at the end of the semester (3.54 vs 2.48, $\mathrm{p}<0.05$ ), as indicated in Table 2. In the PSS subscale, all of the stressor domains were statistically significantly higher among nurses on both occasions. Stress from teachers and nursing staff were scored as a major source among both groups of students at two points $(\mathrm{M} 0=3.75 \mathrm{vs} 2.76$; $\mathrm{M} 1=3.62 \mathrm{vs} 2.53$; $\mathrm{p}<0.05)$, while the student nurses identified more stress from the assignments and workload than did the MLS students (M0 = 3.24 vs 2.27; $\mathrm{M} 1=3.12$ vs $2.01 ; \mathrm{p}<0.05)$, followed by stress from the environment $(\mathrm{M} 0=3.12$ vs 2.07 ; $\mathrm{M} 1=2.97$ vs 1.69 ; $\mathrm{p}<0.05$ ). The nursing students also experienced higher stress levels from taking care of patients than did MLS students (M0: 3.12 vs $1.88 ; \mathrm{M} 1: 3.04$ vs $1.76 ; \mathrm{p}<0.05$ ). The least source of stress in both groups was from peers and daily life (M0 $=2.37$ vs $1.78 ; \mathrm{M} 12.33$ vs $1.64 ; \mathrm{p}<0.05)$, and from lack of professional knowledge and skills (M0 = 2.04 vs 1.47 ; $\mathrm{M} 1=2.12$ vs $1.24 ; \mathrm{p}<0.05)$.

\subsection{Difference in the Coping Mechanisms Used Between Nursing and MLS Students at Baseline and End of the Semester}

There were variations in the degree of total coping behaviour used by nursing and MLS students at two points of assessment, as presented in Table 3. The most common type of coping behaviour for nursing students at baseline were avoidance, whilst this coping mechanism was the least used by MLS students (M0 $=3.54$ vs M0 $=1.47$; $\mathrm{p}<0.05$ ). Problem-solving strategies scored higher among MLS students at baseline ( $\mathrm{M} 0=3.62$ vs $2.15 ; \mathrm{p}<0.05)$. However, both groups equally used the coping behaviour of keeping optimistic and having a positive attitude in dealing with everything in life. Transference was the minimal type of used coping method among the study participants.

\subsection{Coping Mechanism and perceived Stress Levels}

Pearson's product-moment correlation coefficient was used to determine the relationship between the levels of perceived stress and the adoption of coping strategies. The results indicated that at the baseline MLS students commonly used problem solving and staying optimistic; at the end of the semester they were correlated significantly with teachers and nursing staff $(r=0.24$ vs 0.21$)$, assignments and workload $(r=0.31$ vs $r=0.27)$, 
clinical environment ( 0.23 vs 0.19$)$, and peers and daily life ( $r=0.29$ vs 0.24$)$. However, correlation with taking care of patients was non-significant.

The utilisation of avoidance, problem solving and staying optimistic was significantly correlated among the nursing students and it is also positively correlated with stress from peers and daily life $(\mathrm{r}=0.22,0.27$ and 0.20 , respectively). Furthermore, problem solving was also correlated significantly and positively with stress from teachers and nursing staff $(\mathrm{r}=0.23)$. However, transference correlated significantly and positively only with stress from clinical environment $(r=0.27)$.

Additionally, a significant correlation was detected between perceived stress and the students' GPA ( $\mathrm{r}=0.35$ vs $0.29 ; \mathrm{p}<0.05)$, and their education level in the college $(\mathrm{r}=-0.37$ vs $0.41 ; \mathrm{p}<0.05)$ with advanced-level students perceiving lower stress levels. The type of programme enrolled in was significantly correlated with perceived stress level $(r=0.27 ; p<0.05)$, with nursing students expressing higher stress levels. Furthermore, with regard to students' choice of nursing $(\mathrm{r}=-0.35, \mathrm{p}<0.05)$, those who had decided to study in medical discipline experienced lower levels of stress. Living status was correlated significantly with intensity of stress perceived $(r=0.29$; $\mathrm{p}<0.05)$. The coping behaviours were correlated positively with education level in the college $(r=0.27, p<0.05)$ and negatively with status of living at home $(\mathrm{r}=-0.28, \mathrm{p}<0.05)$, suggesting that students who reside at home alone or with colleagues were more likely to use coping mechanisms.

\section{Discussion}

To the best of our knowledge, this is the first study to compare the level of stress experienced and the coping mechanisms adopted between nursing and MLS students at the beginning and end of the semester. The current study described the intensity of the perceived stress level, stressor and coping mechanisms adopted to ameliorate the effects of stress. The results indicated that there is a statistically significant difference in the perceived stress level and coping mechanisms between nursing and MLS students at both points. Few other studies have compared perceived stress levels and coping mechanisms between professional healthcare students.

The greatest source of stress among student nurses was teachers and nursing staff, but this was not the case for MLS students. This due to that the majority of nursing teachers, clinical preceptors and nursing staff are expatriates, with different cultural backgrounds, language and teaching styles. However, MLS teachers and lab technicians are Saudi, with a similar culture and teaching style familiar to MLS students. However, stress from relationships with academic faculty is widely available in health-related professions (Bradshaw et al., 2018; Subhi Al-Zayyat \& Al-Gamal, 2014; Zhao et al., 2015). In the current study, the inconsistency between students' and teachers' expectations might explain the stress from teachers. Clinical objectives of the clinical course should be communicated clearly to students. This finding is contradicted previous studies which found stress from teachers and nursing staff were not the highest stressors (Hamaideh et al., 2017; McCarthy et al., 2018). This discrepancy is explained by the nature of their participants as they recruited advanced-level students and collected data only at in the start of the academic year.

The current study showed that the assignments and workload were the second highest stressor, especially among the student nurses. This is consistent with the results of other studies (Alsaqri, 2017; Bam et al., 2014; Subhi Al-Zayyat \& Al-Gamal, 2014). This may be explained by the largest proportion of the nursing curriculum being devoted to clinical courses in which students are required to submit a minimum of four assignments per course, including a care plan, clinical log, case study and process recordings. The current study plan in the college allows students to enroll in two clinical courses beside another theoretical course, which might increase the level of stress experienced. Taking into consideration the present study results, the coordinators of clinical courses might need to revise the requirements for their courses to handle this problem and create a supportive educational environment; this would also enable students to devote the longest proportion of the clinical course to mastering essential nursing skills.

This result is in line with other qualitative studies who used focus groups and/or semi-structured interviews to explore stress among student nurses. They found the control and demands of courses were major sources of stress (Galvin \& Smith, 2015, McKenna \& Plummer, 2013). MLS students perceived this stressor less than did nursing students. This might be attributed to the variation in study plans in both sciences as the total proportion of clinical courses in MLS is far less than in nursing. This finding is similar to those of Zhao et al. (2015) and Galvin and Smith (2015), who stated that the significant amount of time students spent on writing these assignments was described as stressful.

The stress of taking care of patients was higher among nursing than MLS students, perhaps because of their different roles in clinical courses as nurses interact with patients, families and other health professionals. MLS 
students in clinical courses deal with samples and machines rather than patients. This corroborates the findings of many previous studies which reported that medical and nursing students experienced higher levels of stress than engineering students (Behere et al., 2011; Mivšek et al., 2018).

Coping with stress for a student nurse is a dynamic and ongoing process, aimed at survival, growth and maintenance of the individual integrity (Labrague et al., 2017). In the current study, the most frequent coping strategies employed were initially avoidance, although problem-solving strategies were commonly cited by the end of the semester. In contrast, MLS students frequently cited problem-solving techniques to handle stress. These results are likely to be related to the different study plans, as the student nurses are exposed to clinical training at a much earlier stage than the MLS students.

Moreover, the nature of student nurses' tasks requires continuous contact, monitoring and delivering care to patients, while MLS students' training is mainly focused on performing laboratory tests. These findings agree with those of Subhi Al-Zayyat and Al-Gamal (2014) and Tully (2004), who identified avoidance as the most utilized coping strategy. However, the current study's findings are not consistent with those of Alsaqri (2017), who indicated that problem solving is the most common coping strategy used by student nurses. Variations in the year of study should also be considered. The predominance of avoidance strategies at baseline and problem-solving strategies later on can be justified by the fact that the current study participants were mainly in their initial years of nursing while in other studies were of advanced students. The more time the students spend in clinical settings, the more learning opportunities are developed. Hence, the students in Tully's investigation were limited in relation to learning opportunities to hone problem-solving skills, and, as a result, avoidance was the primary coping strategy they employed. Chan et al. (2014) showed that nursing students who had previous clinical learning opportunities were able to utilize problem solving to handle stressors.

According to the demand-control model of stress in the work environment (Karesek \& Theorell, 1990), undesirable stress occurs in circumstances with a high level of external demands in combination with a low level of individual control. This is possibly the case in overloaded departments and therefore explains why the students experienced an increased level of stress there. The results of this study indicate that clinical instructors and coordinators who have a vital role in the clinical education should be aware of the fact that students who practice in hospital departments are at high risk of stress. Some students might need prolonged support during their clinical exposure. On the other hand, stress levels were mild among Greek student nurses. Mild stress levels can be helpful to the individual's health, particularly when confronted with challenge and responsibility.

The findings of the current study have important clinical implications. Faculty members and curriculum development committees should make a positive contribution towards reducing the stress of student nurses. In addition, the results support the need to prepare students with basic knowledge and skills in the college lab before clinical practice, with full orientation regarding hospital environments, staff and policies of the clinical training places. It is also indicated that nursing teachers and clinical nurses must have knowledge in dealing with stress among their students and they must serve as a good role model. This can be achieved by conducting workshops early in the semester to teach students about stress management and coping skills. The nursing curriculum should be proactive in equipping student nurses with effective coping skills, which can be called upon in their future nursing careers.

The study has some limitations. First, data were collected from study participants during specific semester in the college, so students who were not present at the time might have had different responses. Second, the outcome measures used in the study were presented in a structured questionnaire, restricting the depth of understanding of students' reactions to the stressors and the purpose of specific coping strategies. Therefore, adding a qualitative approach would improve the rigour of further study designs and enhance the validity of the findings.

\section{Conclusion}

Stress has become an imperative part of daily life. The clinical environment is an important part of any undergraduate nursing curriculum. In this study, the most common stressor was clinical assignments and workload. Nursing students perceived high stress levels and employed ineffective coping strategies compared with MLS students.

\section{Competing Interests Statement}

The authors declare that there are no competing or potential conflicts of interest.

\section{References}

Ab Latif, R., \& Nor, M. Z. M. (2016). Stressors and coping strategies during clinical practices among diploma 
nursing students. Education in Medicine Journal, 8(3). https://doi.org/10.5959/eimj.v8i3.422

Al-Lamki, L. (2010). Stress in the Medical Profession and its roots in Medical School. Sultan Qaboos University Medical Journal, 10(2), 156.

Alsaqri, S. H. (2017). Stressors and Coping Strategies of the Saudi Nursing Students in the Clinical Training: A Cross-Sectional Study. Education Research International, 2017. https://doi.org/10.1155/2017/4018470

Bam, V., Oppong, G., \& Ibitoye, M. (2014). Stress and coping mechanisms of nursing students during clinical practice in Ghana. Journal of Science and Technology (Ghana), 34(2), 50-59. https://doi.org/10.4314/just.v34i2.6

Behere, S. P., Yadav, R., \& Behere, P. B. (2011). A comparative study of stress among students of medicine, engineering, and nursing. Indian journal of psychological medicine, 33(2), 145. https://doi.org/10.4103/0253-7176.92064

Bradshaw, C., Tighe, S. M., \& Doody, O. (2018). Midwifery students' experiences of their clinical internship: A qualitative descriptive study. Nurse education today, 68, 213-217. https://doi.org/10.1016/j.nedt.2018.06.019

Braga, P. C. V., Souza, L. A. F., Evangelista, R. A., \& Pereira, L. V. (2012). The occurrence of headaches and their effect upon nursing undergraduate students. Revista da Escola de Enfermagem da USP, 46(1), 138-144. https://doi.org/10.1590/S0080-62342012000100019

Brown, J., \& Marshall, B. L. (2008). A historically Black university's baccalaureate enrollment and success tactics for registered nurses. Journal of Professional Nursing, 24(1), 21-29. https://doi.org/10.1016/j.profnurs.2007.06.006

Burnard, P., Edwards, D., Bennett, K., Tothova, V., Baldacchino, D., Bara, P., \& Mytevelli, J. (2008). A comparative, longitudinal study of stress in student nurses in five countries: Albania, Brunei, the Czech Republic, Malta and Wales. Nurse Education Today, 28(2), 134-145. https://doi.org/10.1016/j.nedt.2007.04.002

Cameron, J., Roxburgh, M., Taylor, J., \& Lauder, W. (2011). Why students leave in the UK: an integrative review of the international research literature. Journal of Clinical Nursing, 20(7-8), 1086-1096. https://doi.org/10.1111/j.1365-2702.2010.03328.x

Chan, C.K., So, W. K., \& Fong, D. Y. (2014). Hong Kong baccalaureate nursing students' stress and their coping strategies in clinical practice. Journal of professional Nursing, 25(5), 307-313. https://doi.org/10.1016/j.profnurs.2009.01.018

Chernomas, W. M., \& Shapiro, C. (2013). Stress, depression, and anxiety among undergraduate nursing students. International Journal of Nursing Education Scholarship, 10(1), 255-266. https://doi.org/10.1515/ijnes-2012-0032

Deasy, C., Coughlan, B., Pironom, J., Jourdan, D., \& Mannix-McNamara, P. (2014). Psychological Distress and Coping amongst Higher Education Students: A Mixed Method Enquiry. Plos One, 9(12). https://doi.org/10.1371/journal.pone.0115193

Elias, H., Ping, W. S., \& Abdullah, M. C. (2011). Stress and academic achievement among undergraduate students in Universiti Putra Malaysia. Procedia-Social and Behavioral Sciences, 29, 646-655. https://doi.org/10.1016/j.sbspro.2011.11.288

Folkman, S., \& Lazarus, R. S. (1980). An analysis of coping in a middle-aged community sample. Journal of health and social behavior, 219-239. https://doi.org/10.2307/2136617

Galvin, J., \& Smith, A. P. (2015). Stress in UK mental health training: a multi-dimensional comparison study. Br J Educ Soc Behav Sci, 9(3), 161-175. https://doi.org/10.9734/BJESBS/2015/18519

Gibbons, C., Dempster, M., \& Moutray, M. (2011). Stress, coping and satisfaction in nursing students. Journal of Advanced Nursing, 67(3), 621-632. https://doi.org/10.1111/j.1365-2648.2010.05495.x

Hamaideh, S.H., Al-Omari, H., \& Al-Modallal, H. (2017). Nursing students' perceived stress and coping behaviors in clinical training in Saudi Arabia. Journal of Mental Health, 26(3), 197-203. https://doi.org/10.3109/09638237.2016.1139067

Karesek, R., \& Theorell, T. (1990). Healthy work. Stress, productivity and the reconstruction of work life. New York: Basic Books.

Kaviani, H., Pournaseh, M., Sayadlou, S., \& Mohammadi, M. (2007). Effectiveness of stress management training 
in reducing anxiety and depression, participants in class exam. New Journal of Cognitive Sciences, 8(2), 61-68.

Kuoppala, J., Lamminpää, A., Liira, J., \& Vainio, H. (2008). Leadership, job well-being, and health effects-a systematic review and a meta-analysis. Journal of occupational and environmental medicine, 50(8), 904-915. https://doi.org/10.1097/JOM.0b013e31817e918d

Labrague, L., McEnroe-Petitte, D., Al Amri, M., Fronda, D., \& Obeidat, A. (2017). An integrative review on coping skills in nursing students: implications for policymaking. International nursing review. https://doi.org/10.1111/inr.12393

Lazarus, R., \& Folkman, S. (1984). Stress, appraisal and coping. Springer Publishing company, Newyork.

Lazarus, R. S., \& Folkman, S. (1987). Transactional theory and research on emotions and coping. European Journal of personality, 1(3), 141-169. https://doi.org/10.1002/per.2410010304

McCarthy, B., Trace, A., O'Donovan, M., O'Regan, P., Brady-Nevin, C., O'Shea, M., ... \& Murphy, M. (2018). Coping with stressful events: A pre-post-test of a psycho-educational intervention for undergraduate nursing and midwifery students. Nurse education today, 61, 273-280. https://doi.org/10.1016/j.nedt.2017.11.034

McCarthy, B., Trace, A., O'Donovan, M., Brady-Nevin, C., Murphy, M., O'Shea, M., \& O'Regan, P. (2018). Nursing and midwifery students' stress and coping during their undergraduate education programmes: An integrative review. Nurse education today, 61, 197-209. https://doi.org/10.1016/j.nedt.2017.11.029

McKenna, L., \& Plummer, V. (2013). Indonesian student nurses' perceptions of stress in clinical learning: A phenomenological study. Journal of Nursing Education and Practice, 3(5), 56. https://doi.org/10.5430/jnep.v3n5p56

Mivšek, P., Äimälä, A.-M., Žvanut, B., \& Tuomi, J. (2018). Midwifery students' well-being among undegraduates in Slovenia: A pilot study. Midwifery, 61, 63-65. https://doi.org/10.1016/j.midw.2018.02.020

Nayomi, W. (2016). Workplace stress in nursing: a literature review.

Nechita, F., Streba, C., Vere, C., Nechita, D., \& Rogoveanu, I. (2014). Stress in Romanian First Year Nursing Students. Current health sciences journal, 40(3), 210.

Nolan, G., \& Ryan, D. (2008). Experience of stress in psychiatric nursing students in Ireland. Nursing standard, 22(43), 35-43. https://doi.org/10.7748/ns2008.07.22.43.35.c6583

Pryjmachuk, S., \& Richards, D. A. (2007). Predicting stress in pre-registration nursing students. British Journal of health psychology 12 (1), 125-144. https://doi.org/10.1348/135910706X98524

Pulido-Martos, M., Augusto-Landa, J., \& Lopez-Zafra, E. (2012). Sources of stress in nursing students: a systematic review of quantitative studies. International Nursing Review, 59(1), 15-25. https://doi.org/10.1111/j.1466-7657.2011.00939.x

Seyedfatemi, N., Tafreshi, M., \& Hagani, H. (2007). Experienced stressors and coping strategies among Iranian nursing students. BMC nursing, 6(1), 1. https://doi.org/10.1186/1472-6955-6-11

Shaban, I. A., Khater, W. A., \& Akhu-Zaheya, L. M. (2012). Undergraduate nursing students' stress sources and coping behaviours during their initial period of clinical training: A Jordanian perspective. Nurse Education in Practice, 12(4), 204-209. https://doi.org/10.1016/j.nepr.2012.01.005

Sheu, S., Lin, H. S., \& Hwang, S. L. (2002). Perceived stress and physio-psycho-social status of nursing students during their initial period of clinical practice: the effect of coping behaviors. International Journal of Nursing Studies, 39(2), 165-175. https://doi.org/10.1016/S0020-7489(01)00016-5

Sheu, S., \& Lin, H. S. (1997). The development and testing of perceived stress scale of clinical practice. Nursing Research, 5, 341-351.

Singh, A., Chopra, M., Adiba, S., Mithra, P., Bhardwaj, A., Arya, R., Chikkara, P., Rathinam, R. D., \& Panesar, S. (2013). A descriptive study of perceived stress among the North Indian nursing undergraduate students. Iranian journal of nursing and midwifery research, 18(4), 340.

Subhi Al-Zayyat, A., \& Al-Gamal, E. (2014). Perceived stress and coping strategies among Jordanian nursing students during clinical practice in psychiatric/mental health courses. International Journal of Mental Health Nursing, 23(4), 326-335. https://doi.org/10.1111/inm.12054

Tully, A. (2004). Stress, sources of stress and ways of coping among psychiatric nursing students. Journal of 
Psychiatric and Mental Health Nursing, 11, 43-47. https://doi.org/10.1111/j.1365-2850.2004.00682.x

Tully, A. (2004). Stress, sources of stress and ways of coping among psychiatric nursing students. Journal of Psychiatric and Mental Health Nursing, 11(1), 43-47. https://doi.org/10.1111/j.1365-2850.2004.00682.x

Yamashita, K., Saito, M., \& Takao, T. (2012). Stress and coping styles in Japanese nursing students. International journal of nursing practice, 18(5), 489-496. https://doi.org/10.1111/j.1440-172X.2012.02056.x

Yusoff, M. S. B., Rahim, A. F. A., \& Yaacob, M. J. (2010). Prevalence and sources of stress among Universiti Sains Malaysia medical students.

Zhao, F. F., Lei, X. L., He, W., Gu, Y. H., \& Li, D. W. (2015). The study of perceived stress, coping strategy and self-efficacy of Chinese undergraduate nursing students in clinical practice. International journal of nursing practice, 21(4), 401-409. https://doi.org/10.1111/ijn.12273

\section{Copyrights}

Copyright for this article is retained by the author(s), with first publication rights granted to the journal.

This is an open-access article distributed under the terms and conditions of the Creative Commons Attribution license (http://creativecommons.org/licenses/by/4.0/). 